\title{
Afogamentos e agressões: considerações nos dados do Datasus para a Região Metropolitana de Manaus (RMM)
}

Drowning and aggression: considerations in Datasus data for the Metropolitan Region of Manaus (RMM)

Ahogamiento y agresión: consideraciones en los datos de Datasus para la Región Metropolitana de Manaus (RMM)

Rúbia Silene Alegre Ferreira ORCID: https://orcid.org/0000-0001-6786-9948 Universidade do Estado do Amazonas, Brasil E-mail: bialegre@ig.com.br

James Barros Monteiro ORCID: https://orcid.org/0000-0003-3978-5151

Centro Universitário do Norte, Brasil

E-mail: Jamesmonteiro74@gmail.com

Andrea Cintia Fernandes Barreto ORCID: https://orcid.org/0000-0001-6272-6075 Universidade do Estado do Amazonas, Brasil E-mail: acbarreto@uea.edu.br

Mary Helem Costa de Sales ORCID: https://orcid.org/0000-0003-3782-3564 Universidade do Estado do Amazonas, Brasil E-mail: mcsales@uea.edu.br

Sabrina Helena Sales da Cruz ORCID: https://orcid.org/0000-0001-8724-6086 Universidade do Estado do Amazonas, Brasil E-mail: shsc.dir17@uea.edu.br

Edimilton Araújo de Castro ORCID: https://orcid.org/0000-0002-9529-1386 Universidade do Estado do Amazonas, Brasil E-mail: Professoredimiltoncastro@gmail.com

Everaldo Nogueira de Souza ORCID: https://orcid.org/0000-0003-4744-4015 Universidade do Estado do Amazonas, Brasil E-mail: ensouza-@hotmail.com

Guirlene da Silva Pinheiro

ORCID: https://orcid.org/0000-0002-3432-165X Universidade do Estado do Amazonas, Brasil E-mail: guirlenedasilvapinheiro@gmail.com

\section{Resumo}

O presente trabalho faz observações relacionadas às mortes por causas externas na Região Metropolitana de Manaus (RMM). Especificamente observa esta questão com foco nos afogamentos e submersões acidentais e agressões. O período compreendido é de 1996 a 2019, com dados extraídos do Sistema de Informação de Mortalidade (SIM/Datasus). Os resultados apontam que as peculiaridades geográficas do estado do Amazonas colaboram para os índices de afogamentos nestas cidades e que há a necessidade de se trabalhar políticas públicas educativas voltadas para os cuidados com as atividades desenvolvidas sobre as águas e por meio dela. De outro modo, mostra ainda que as agressões são uma das causas de morte que se eleva na linha de tempo estudado, o que retrata que se trata de uma anomalia que atinge significativa parcela da sociedade.

Palavras-chave: Afogamentos; Agressões; Região Metropolitana de Manaus.

\footnotetext{
Abstract

The present work makes observations related to deaths from external causes in the Metropolitan Region of Manaus (RMM). Specifically, it looks at this issue with a focus on accidental drownings and submersions and assaults. The period covered is from 1996 to 2019, with data extracted from the Mortality Information System (SIM/Datasus). The results show that the geographic peculiarities of the state of Amazonas contribute to the drowning rates in these cities
} 
and that there is a need to work on educational public policies aimed at caring for the activities carried out on and through water. Otherwise, it also shows that aggressions are one of the causes of death that rises in the studied timeline, which shows that this is an anomaly that affects a significant portion of society.

Keywords: Drownings; Aggressions; Metropolitan Region of Manaus.

\section{Resumen}

El presente trabajo realiza observaciones relacionadas con muertes por causas externas en la Región Metropolitana de Manaus (RMM). Específicamente, analiza este tema con un enfoque en ahogamientos accidentales, inmersiones y asaltos. El período cubierto es de 1996 a 2019, con datos extraídos del Sistema de Información de Mortalidad (SIM / Datasus). Los resultados muestran que las peculiaridades geográficas del estado de Amazonas contribuyen a las tasas de ahogamiento en estas ciudades y que existe la necesidad de trabajar en políticas públicas educativas orientadas a cuidar las actividades que se realizan sobre y a través del agua. De lo contrario, también muestra que las agresiones son una de las causas de muerte que se eleva en la línea de tiempo estudiada, lo que demuestra que se trata de una anomalía que afecta a una parte importante de la sociedad.

Palabras clave: Ahogamientos; Agresiones; Región Metropolitana de Manaus.

\section{Introdução}

O estado do Amazonas é uma das unidades das federações que apresenta relativa peculiaridade: abundancia de águas. Essa característica é presente em todos os municípios e se constitui em fases que marcam pelo menos dois importantes eventos, que dizem respeito ao período das cheias e o das vazantes. Assim, tem-se um cenário que se replica e se percebe no tocante às mortes por causas externas: um deles é o afogamento e submersão acidentais, pois dadas fatalidades ocorrem cobrindo várias faixas etárias. Não exatamente pelo fato de subida e descida das águas, mas em função de se ter tanta água no estado, que a vida segue em atividades (sejam elas econômicas ou de lazer) sobre as águas. Desse modo diversas questões no dia a dia das pessoas, têm relação com os eventos que ocorrem nestas áreas.

Para Kanso (2016), uma das maiores transformações sociais ocorridas no século XX foi a queda da mortalidade. Embora tenha sido generalizada, ocorreu de forma distinta (velocidade, intensidade e timing) entre grupos de idade e causas. Iniciou-se entre os mais jovens, principalmente crianças, em razão da redução dos óbitos por doenças infecciosas e parasitárias, em um segundo momento, na população adulta e, posteriormente, nas pessoas com idades mais avançadas, nas quais predominavam os óbitos devido às doenças crônicas. Essas mudanças ocorridas ao longo dos anos estavam associadas não somente à transição demográfica, mas também à epidemiológica.

No entanto, é consenso entre pesquisadores da área demográfica/econômica, que a eleavação das mortes por causas externas, tem se constituído uma importante preocupação, (Leite 2017; Waiselfisz 2012; Camarano et al., 1997; Oliveira \& Albuquerque, 2005; Cerqueira \& Moura, 2013). As agressões, segundo elemento aqui estudado, constituem-se em importante problema a ser resolvido para elevação do bem-estar da sociedade. Segundo Nóbrega Jr et al (2011), política pública é uma decisão de cunho estritamente político que visa distribuir recursos públicos escassos para aquilo que o grupo que controla o aparelho de Estado julga mais importante. A Segurança Pública é uma das mais importantes políticas de segurança que o Estado democrático precisa implementar, pois lida com a vida e a morte de indivíduos. Afinal, teoricamente, aproximando os cidadãos da lei, a democracia deveria protegê-los melhor.

Do total de óbitos entre os jovens brasileiros, essas foram responsáveis por 50,0\%, em 1980, e por 69,6\%, em 2010 . Nesse período, foi observada uma redução nas proporções de óbitos por todas as causas, à exceção daqueles decorrentes de causas externas. Em números absolutos, estes óbitos cresceram 120\%. Entre as principais causas de morte de homens jovens, as externas em 1980 foram responsáveis por 61,5\% do total de óbitos e em 2010, por 77,9\%. Este aumento se deu principalmente pelo aumento dos homicídios, conforme Kanso (2016).

De acordo com Cerqueira e Moura (2014), no plano individual, há um consenso na literatura de que a criminalidade violenta está fortemente relacionada ao sexo masculino, num ciclo que se inicia na pré-adolescência e atinge seu auge entre 18 
e 24 anos. Entretanto, em termos agregados, as consequências de mudanças na estrutura demográfica sobre a criminalidade violenta, ainda são objeto de intensa discussão na academia.

De acordo com Kritensen (2003) e Grisso (1996), os indivíduos não agridem por causa de sua biologia, embora possuam um aparato perceptual e motor para proceder assim. São as experiências sociais ao longo do desenvolvimento os determinantes de nossa cognição, bem como do substrato neural que possibilita o processamento das informações. E são justamente essas experiências que vão direcionar o organismo para interpretar as informações ambientais como potencialmente ameaçadoras e se comportar de forma mais ou menos agressiva. Assim, a agressão é tanto uma consequiência da neuroadaptação aos fatores psicossociais e ambientais, quanto uma conseqüência dos efeitos biológicos no desenvolvimento psicossocial.

Nesse sentido, Cerqueira e Moura (2014) apontam que existem outros elementos importantes, quando se pondera as questões da disseminação das agressões ou que atuam como facilitadores, que são:

i) o descontrole das armas de fogo;

ii) a impunidade;

iii) a não efetividade do sistema de justiça criminal; e

iv) a política de encarceramento em massa que, ao não separar os detentos por grau de periculosidade, termina por disseminar uma subcultura e a tecnologia criminosa.

Em relação aos afogamentos, pode-se partir da definição tida a respeito. Na fala de Szpilman (2000), afogamento (drowning) é definido como resultado de asfixia por imersão ou submersão em qualquer meio líquido, provocado pela entrada de água em vias aéreas, dificultando parcialmente ou por completo a ventilação ou a troca de oxigênio com o ar atmosférico.

Este tipo de acidente é de grande importância desde o princípio de nossa civilização, com inúmeras citações na bíblia, embora apenas nas últimas decadas tenha ganho a atenção científica e a preocupação que merece. Ironicamente, $90 \%$ de todos os casos de afogamento ocorrem a 10m de uma medida de segurança instalada. Estimativas indicam que 40 a $45 \%$ ocorrem durante a natação e 12 a 29\% estão associados com o uso de barcos. Na prática de esportes náuticos, os afogamentos são responsáveis por 90\% dos óbitos, (Szpilman, 2000; Branche, 1998; Denicola, 1997).

Em Ferreira et al (2021), há resultados de que se perde uma juventude significativa no quesito mortes por agressão. Dos sete grupos estudados, tanto para homens quanto para mulheres, três destes são os que se destacam com os maiores eventos: 15 a 19; 20 a 29 e 30 a 39 anos. Mostraram ainda, que à medida que a escolaridade se eleva, as mortes decorrentes de agressão são menores apontando que a instrução (seja ela no nível que for) pode ser um coadjuvante que axuilie na redução das perdas.

Segundo Jorge et al (2021), as causas externas representam importante fator na mortalidade do Brasil. Conhecer quem é vulnerável e quais os motivos disso constituem um elemento fundamental para políticas de prevenção de acidentes e violências. Para que esses programas sejam efetivos, é necessário um detalhamento sobre as reais causas de morte. Desta forma, busca-se neste trabalho fazer observações relacionadas às mortes por causas externas na Região Metropolitana de Manaus (RMM). Detidamente, se observa esta questão com foco nos afogamentos e submersões acidentais e agressões, em uma linha de tempo que inicia em 1996 e se estende até o ano 2019, com dados extraídos do Sistema de Informação de Mortalidade (SIM/Datasus).

Tem-se a seguinte estruturação, além desta introdução: faz-se na revisão bibliográfica, ligeira abordagem a respeito da teoria relacionada ao tema. Na seção metodologia, apresenta-se a origem dos dados, o tipo de pesquisa e o local estudado. Em seguida, na discussão dos resultados, demonstra-se os achados obtidos na pesquisa e por fim, tece-se as considerações finais. 


\section{Metodologia}

A pergunta fundamental sobre um método, não é se, e quanto, ele é verdadeiro, mas se, e quanto, ele é útil para arar o terreno empírico que temos em frente. Em outras palavras, nosso juízo sobre o valor do método deve ser relacionado à sua fertilidade para nos aproximar da realidade estudada, Conforme Serapione, (2000) e Perrone (1997).

Em se tratando de pesquisa qualitativa e quantitava, Sarapione (2000) afirma que uma vez que se aceite a complementaridade entre as duas abordagens e a forma de propor alguma integração, a partir do reconhecimento das especificidades de cada uma, é possível identificar de que maneira podem ser mais bem incorporadas ao desenho da pesquisa. Assim, os métodos qualitativos devem ser utilizados quando o objeto de estudo não é bem conhecido. Por sua capacidade de fazer emergir aspectos novos, de ir ao fundo do significado e de estar na perspectiva do sujeito, são aptos para descobrir novos nexos e explicar significados. De fato, durante a pesquisa, freqüentemente emergem relações entre variáveis, motivações e comportamentos completamente inesperados, que não surgiriam utilizando um questionário estruturado, cuja característica técnica é a uniformidade do estímulo. Segundo o autor ${ }^{1}$, na pesquisa quantitativa, por sua vez: são orientados à busca da magnitude e das causas dos fenômenos sociais, sem interesse pela dimensão subjetiva e utilizam procedimentos controlados; são objetivos e distantes dos dados (perspectiva externa, outsider), orientados à verificação e são hipotético-dedutivos; assumem uma realidade estática; são orientados aos resultados, são replicáveis e generalizáveis.

\subsection{O local da pesquisa}

A Região Metropolitana de Manaus (RMM) é formada por oito municípios que se agrupam em seu entorno. Entre eles, tem-se: Manaus, a capital do Amazonas, Rio Preto da Eva, Presidente Figueiredo e Itacoatiara. A partir da Ponte sobre o Rio Negro, os demais estão localizados, que são: Iranduba, Manacapuru, Novo Airão. O último a integrar o grupo, Careiro da Várzea, localiza-se às margens do Rio Solimões. Na Figura 1 tem-se a demonstração dos municípios em estudo:

Figura 1 - Mapa dos municípios da Região Metropolitana de Manaus (RMM).

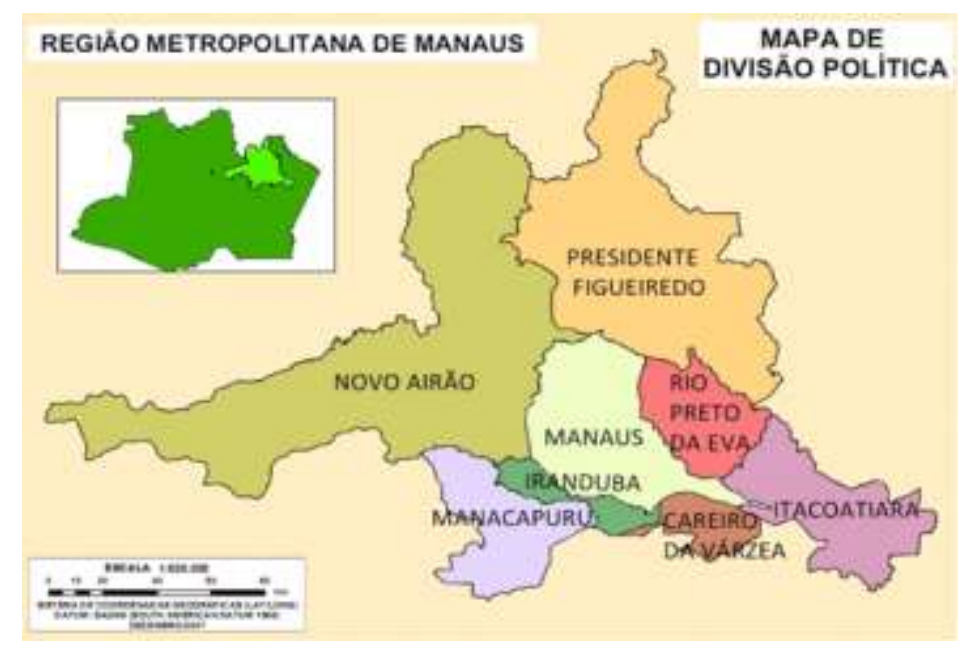

Fonte: Google Maps.

São sete cidades que possuem dada proximidade da capital Manaus e por conta disso, há intensa mobilidade populacional entre estes. A Região Metropolitana de Manaus, foi criada pela Lei Complementar Estadual n ${ }^{\circ} 52$, de 30 de maio de 2007, (Silva \& Galvão, 2017).

\footnotetext{
${ }^{1}$ Serapione (2000)
} 


\subsection{Os dados}

A pesquisa utiliza uma tendência de séries históricas, nomeadas pela Classificação Internacional de Doenças (CID), conformando as ocorrências de óbitos relacioados aos afogamentos e submersão acidentais e agressões. São fatalidades classificadas como "causas externas".

Os dados estão disponíveis no endereço eletrônico do Departamento de Informática do SUS (Datasus). Para tanto, utilizou-se o Sistema de Informação sobre Mortalidade do Ministério da Saúde (SIM-MS). O período de cobertura inicia em 1996 e se estende a 2019 para os casos de óbitos gerais, bem como por faixa etária para os minicípios da Região Metropolitana de Manaus (RMM).

É importante que se tenha uma dada previsão, embora aproximada, daquilo que se pode vir a enfrentar no futuro. As previsões são de grande importância quando nos deparamos com fenômenos nos quais a incerteza é um fator presente. Existem diversos métodos de previsão e cada um tem sua aplicabilidade, dependendo do que se está interessado estudar. Em séries temporais ou série histórica, a amostra é um conjunto de observações ordenadas no tempo e a ordem em que são feitas as medições não pode ser ignorada, (Ferreira et al 2021; Pagani Heringer de Miranda, 2014).

A abordgagem desta pesquisa é de natureza qualitativa e quantitativa. A pesquisa qualitativa não vai medir seus dados, mas, antes, procurar identificar suas naturezas. O objeto da pesquisa vai ser tratado de forma radicalmente diferente da modalidade anterior de investigação. No caso da segunda, faz a descrição rigorosa das informações obtidas é condição vital para uma pesquisa que se pretenda quantitativa, conforme Mezzaroba e Monteiro (2009).

\section{Resultados e Discussão}

Nesta seção se faz a demonstração dos achados em séries históricas, para as duas variáveis pontuadas no estudo: os óbitos por afogamento e submersões acidentais e os decorrentes de agressões. Na questão dos afogamentos e submersões acidentais, uma questão preponderante diz respeito à abundancia de águas da qual desfruta o estado do Amazonas.

\subsection{Séries Históricas para a percepção do objeto em estudo}

Na Figura 2 mostra-se os eventos de afogamentos e submersões acidentais e de agressões para o município Manaus. Faz-se dessa maneira, em função do quantitativo dos dados deste, em relação aos demais ser muito superior, o que dificultaria a compreensão dos dados dos demais. Desse modo, nota-se que os afogamento e submersões acidentais são relativamente menores quando comparado com as agressões. As ocorrências, de certa forma apresentam tendências de redução à medida que o tempo se estende.

É válido mencionar, que em função da abundancia de água que cobre os municípios, o comércio se desenvolve, também sob esta oferta. Assim, além da questão de embarque e desembarque de passageiros, que utilizam as embarcações, tem-se ainda o transporte de mercadorias que circulam, de Manaus para os municípios e destes para Manaus, o que mantém um fluxo de bens e pessoas nestas estruturas, que não proporcionam segurança para os transeuntes e trabalhadores deste segmento. Uma queda das pontes de madeira, pode ser o ponta-pé para a elevação dos óbitos por afogamentos. Além desta situação, temse ainda a questão de que sobre as águas funcionam vários estabelecimentos como bares, balneários, flutuantes comerciais, dentre outros. A situação se replica para os demais municípios do estudo, pois as circuntâncias são as mesmas. 
Figura 2 - Série histórica das causas externas para a capital Manaus.

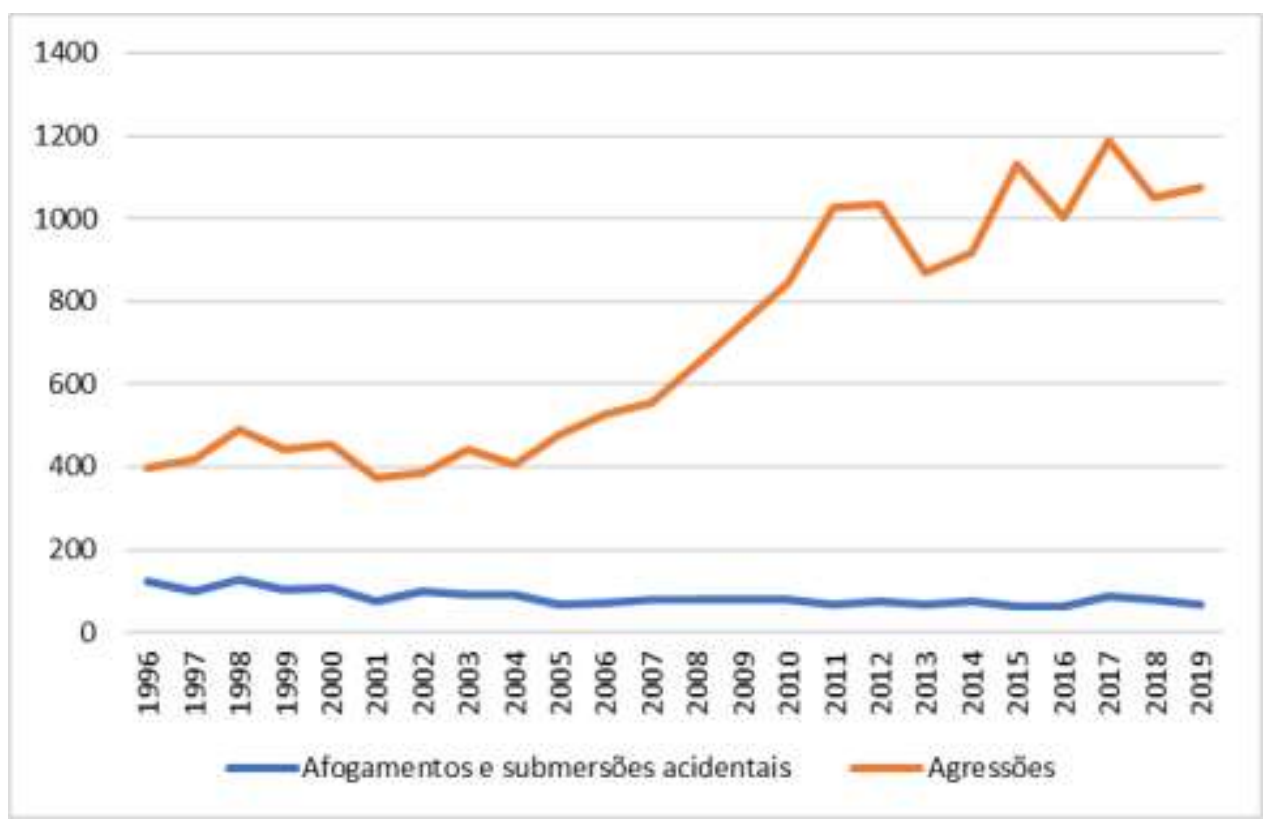

Fonte: SIM/Datasus.

As agressões, por outro lado, assumem uma tendência vertiginosa de crescimento, sobretudo a partir de 2004. A partir de 2011 apresenta picos e reduções, mantendo, no entanto, números superiores 800, alcançando em 2017 o montante de 1.200 óbitos. É o tipo de causa externa que assombra ainda significatia parcela da população brasileira.

Na Figura 3 mostram-se os afogamentos e submersões acidentais, onde Manacapuru, Itacoatiara e Iranduba se destacam com as maiores ocorrências quando se considera as ocorrências (exceto Manaus). Presidente Figueiredo, também apresenta números que se elevam e reduzem durante toda a série histórica, com maiores eventos e 2014 e 2015.

Figura 3 - Série histórica por afogamento e subemersões acidentais - Região Metorpolitana de Manaus.

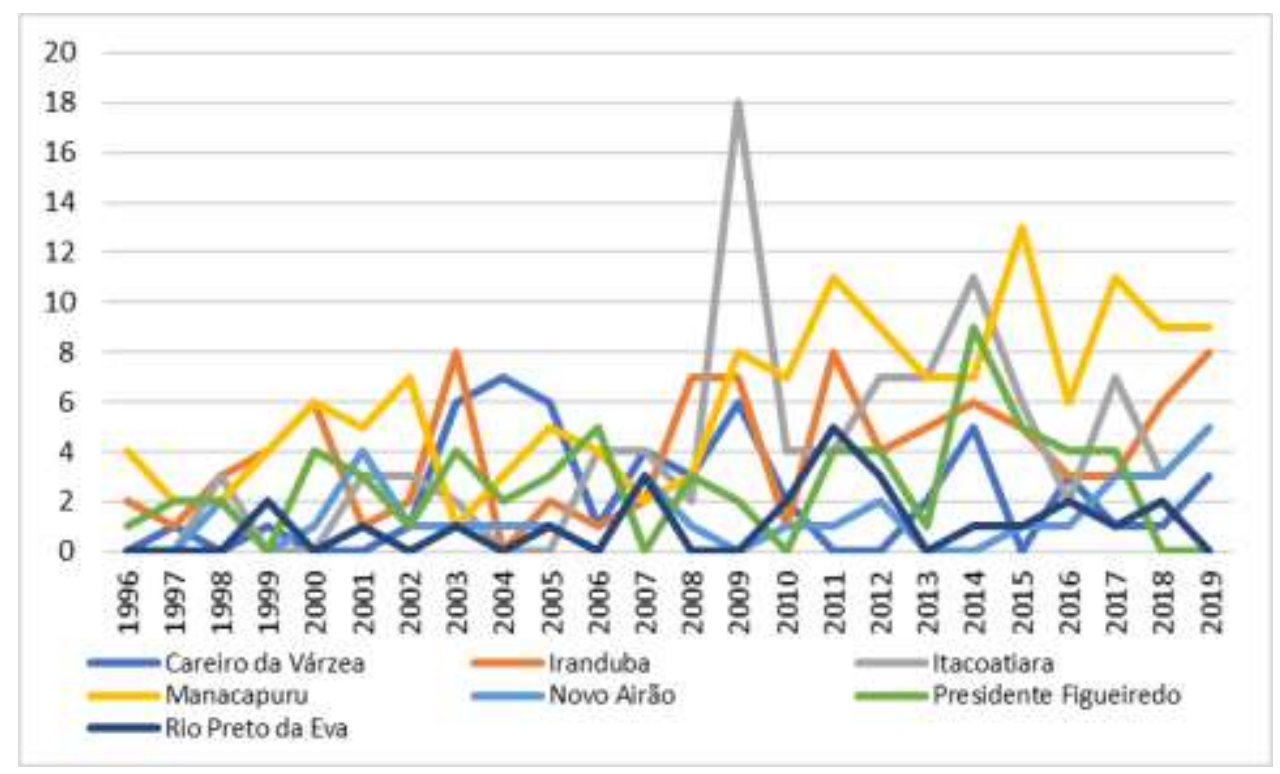

Fonte: SIM/Datasus.

Conforme a Figura 3, Manacapuru ocupa a segunda posição por óbitos em agressão, uma vez que Manaus é a lider (dados na Figura 1). Nos anos 2014, 2015 a 2018 os picos se intensificam. Há um pico percebido no ano de 2009 para 
Itacoatiara $^{2}$. É referente a um naufráfio que se deu na data de 06/04/2009, em função de superlotação da embarcação, caso corriqueiro nas águas do Amazonas.

Na Figura 4, tem-se a disposição dos óbitos decorrentes das agressões na Região Metropolitana de Manaus. Nesta modalidade, Manacapuru é a cidade que nos grupo de sete (exceto Manaus) que ocupa a posição com maiores incidências em tendencia de crescimento. Iranduba, de igual modo mostra elevações nestas causas. Esta cidade, bem como Iranduba e Novo Airão, receberam no ano de 2011 a mobilidade rodoviária pela inauguração da Ponte Jornalista Phelippe Daou ${ }^{3}$, atribuindo ganhos de tempo no deslocamento. Essa questão pode auxiliar no entendimento para a elevação dos casos percebidos a partir desta data, sobretudo em Manacapuru e Iranduba.

Figura 4 - Série histórica por Agressões na Região Metropolitana de Manaus.

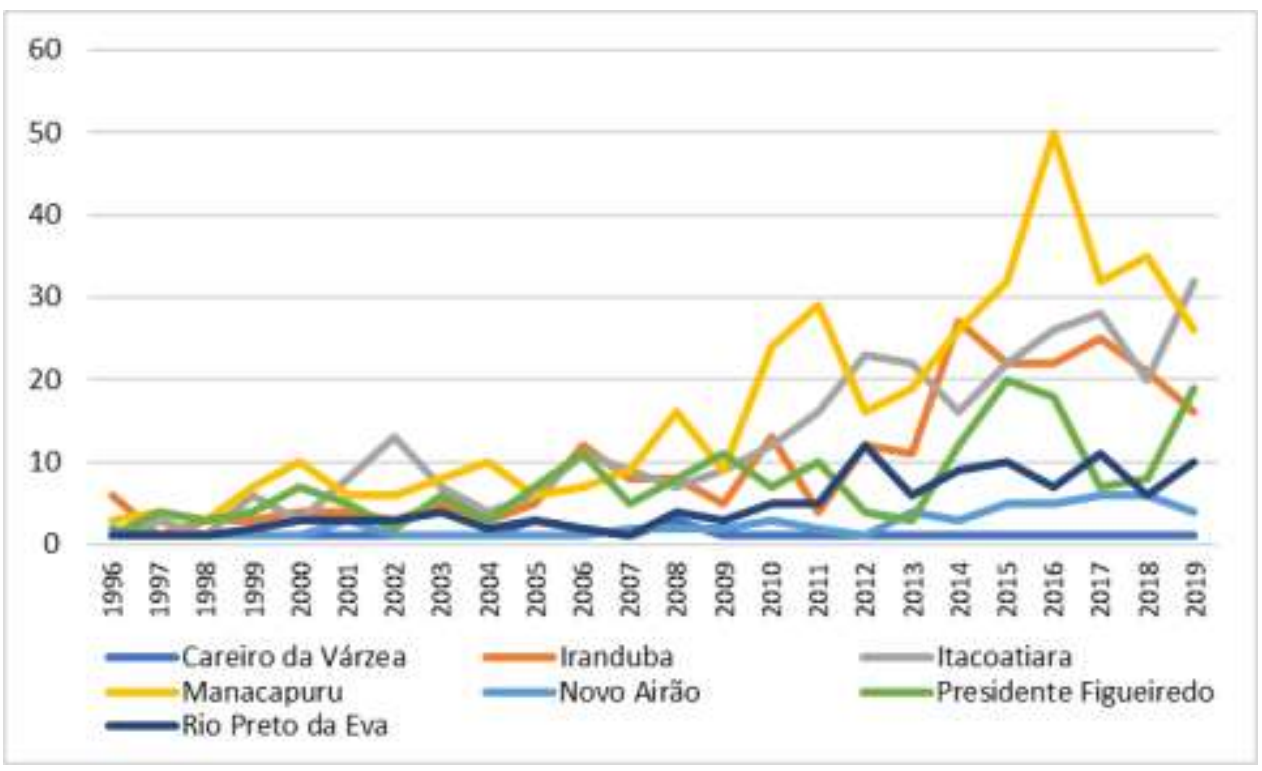

Fonte: SIM/Datasus.

Itacoatiara é um município localizado a 270 kilometros de Manaus, na Rodovia Dep. Vital de Mendonça. Nos 23 anos observados na série histórica, nota-se a mesma tendência de crescimento dos óbitos por agressão até o fim da série. Presidente Figueiredo, município que exerce alta atratividade em função das cachoeiras que concentra, possui significativa mobilidade nos finais de semana e feriados, apresenta volumes menores de óbitos, com elevações em 2015 e 2016 e 2019. Rio Preto da Eva, tem ascensão a partir e 2010 e eleva-se, também para o restante do período na linha de tempo estudada. Careiro da Várzea e Novo Airão, são os dois municípios da RMM que apresentam as menores ocorrências.

\subsection{Afogamentos}

O município Careiro da Várzea, conforme indicação do seu nome, é um das cidades do estado do Amazonas onde o ciclo de águas faz uma intensa relação, pois parte relativa da população mora em casas que se localizam às margens do rio Solimões. A partir deste município se acessa outros tantos municípios, bem como concentra a continuidade da BR 319. Nota-se que para os grupos erários mais novos, são menores as ocorrencias de óbitos. A concentração efetiva é a dos grupos de 30 a 39 anos e 40 a 49 anos, o que diz respeito às fases adultas.

\footnotetext{
${ }^{2}$ https://www.correiobraziliense.com.br/app/noticia/brasil/2009/04/06/interna-brasil,96197/barco-que-naufragou-no-rio-amazonas-elocalizado-a-100-metros-do-local-do-acidente.shtml

${ }^{3}$ Conhecida como Ponte sobre o Rio Negro.
} 
Iranduba, Manacapuru e Novo Airão são cidades que se localizam a partir da Ponte sobre o Rio Negro. São municípios que congregam população que faz um movimento pendular diário à cidade Manaus, dado à proximidade desta. Para o primeiro, neste grupo, os registros de óbitos por afogamento, também fazem relação com os grupos etários medianos. No entanto, embora as incidências sejam menores, estes eventos estão presentes também em grupos mais novos e mais velhos, como no grupo etário de 15 a 19 anos e de 60 a 69 anos.

Tabela 1 - Afogamentos e submersões acidentais por grupo de idade.

\begin{tabular}{|c|c|c|c|c|c|c|c|c|}
\hline & $\begin{array}{c}10 \text { a } 14 \\
\text { anos }\end{array}$ & $\begin{array}{c}15 \text { a } 19 \\
\text { anos }\end{array}$ & $\begin{array}{c}20 \text { a } 29 \\
\text { anos }\end{array}$ & $\begin{array}{c}30 \text { a } 39 \\
\text { anos }\end{array}$ & $\begin{array}{c}40 \text { a } 49 \\
\text { anos }\end{array}$ & $\begin{array}{c}50 \text { a } 59 \\
\text { anos }\end{array}$ & $\begin{array}{c}60 \text { a } 69 \\
\text { anos }\end{array}$ & $\begin{array}{c}70 \text { a } 79 \\
\text { anos }\end{array}$ \\
\hline Careiro da Várzea & 2 & 3 & 4 & 10 & 8 & 3 & 3 & 5 \\
\hline Iranduba & 2 & 6 & 8 & 15 & 15 & 9 & 7 & 3 \\
\hline Manacapuru & 13 & 12 & 25 & 15 & 16 & 9 & 9 & 2 \\
\hline Novo Airão & - & 2 & 1 & 9 & 6 & 1 & 3 & - \\
\hline Manaus & 152 & 277 & 453 & 306 & 200 & 113 & 42 & 16 \\
\hline Presidente Figueiredo & - & 4 & 11 & 13 & 3 & 10 & 5 & 2 \\
\hline Rio Preto da Eva & 2 & 3 & 4 & 4 & 5 & 1 & - & 1 \\
\hline Itacoatiara & 9 & 7 & 14 & 14 & 11 & 8 & 6 & 1 \\
\hline
\end{tabular}

Fonte: SIM/Datasus.

Manacapuru, é o município que possui os maiores registros destas ocorrencias, ficando somente depois de Manaus. Para todos os grupos etários neste item relacionados, a menor ocorrencia se dá para a idade de 70 a 79 anos. Inclusive para os grupos etários mais jovens, que é o caso de 10 a 14 anos, os óbtios são de certa forma, maiores para com os demais. Na Região Metropolitana de Manaus, é o local com participação mais altas para este grupo.

Novo Airão, é um município com relativa área de preservação ambiental e nesse processo, congrega o maior parque do estado (Anavilhanas). A mobilidade populacional para este local se dá por estrada, mas dentro do território, a abundância de águas determina boa parte das atividades. Desta forma, mantendo-se a tendencia de óbtios por afogamentos, nos grupos etários adultos de 30 a 39 e 40 a 49 anos.

Manaus, a capital do Amazonas por ter a maior concentração populacional, responde também pelas quantídades de diversas evidencias a ela relacionadas. Assim, em todo o período observado, nota-se que para todos grupos etários são superiores a todos os demais municípios da Região Metropolitana. O desta que maior se concentra entre 20 a 29 anos, com mais de 450 óbitos por afogamentos. Não obstante, em todas as idades os números são elevados. No porto da Cidade, tem-se intensa movimentação das atividades econômicas, pois os demais municípios são abastecidos por ofertas de mercadorias enviadas pelas embarcações para estas localidades e que também recebe destes.

Presidente Figueiredo é um município com significativo atrativo turístico, com um complexo de cachoeiras que nos finais de semana e feriados promovem um ciclo econômico que emprego e renda. Comparando com os demais municípios, o número é de certa forma baixo. Rio Preto da Eva, que também tem oferta de balneário, apresenta os menores índices de afogamentos da série de municípios da Região Metropolitana. Itacoatiara apresenta números mais elevados, também, na tendencia dos demais municípios, concentrando-se nos grupos etários de 20 a 49 anos. 


\subsection{Agressões}

Considerar as agressões enquanto um óbito por causas externas, nos permite perceber que os todos os grupos etários estudados são afetados. Os adolescentes, do grupo de 10 a 14 anos, embora em menores proporções, mostram que essas pessoas, embora em tão pouca idade, já são coadjuvantes deste tipo de fatalidade.

Manaus, sem dúvida é a cidade que tem a dianteira das agressões na série estudada. No grupo de 20 a 29 anos tem-se o ponto máximo destas ocorrências com mais de 7.300 óbitos e apesar de se reduzir para o próximo grupo, ainda assim tem-se volume elevado (3.750). Nota-se que à medida que idade se eleva, a tendência é de uma redução sistemática destes fatos.

Ao se considerar o grupo etário de 20 a 29 anos, Manacapuru é o segundo na questão destes eventos (154), seguido de Itacoatiara (112), Iranduba (95), Presidente Figueiredo (59) e Rio Preto da Eva (31). Novo Airão (3) e Careiro da Várzea (1), são os que apresentam na série observada, as menores ocorrencias.

Tabela 2 - Agressões por grupos etários.

\begin{tabular}{|c|c|c|c|c|c|c|c|c|}
\hline & $\begin{array}{c}10 \text { a } 14 \\
\text { anos }\end{array}$ & $\begin{array}{c}15 \text { a } 19 \\
\text { anos }\end{array}$ & $\begin{array}{c}20 \text { a } 29 \\
\text { anos }\end{array}$ & 30 a 39 anos & $\begin{array}{c}40 \text { a } 49 \\
\text { anos }\end{array}$ & $\begin{array}{c}50 \text { a } 59 \\
\text { anos }\end{array}$ & $\begin{array}{c}60 \text { a } 69 \\
\text { anos }\end{array}$ & $\begin{array}{c}70 \text { a } 79 \\
\text { anos }\end{array}$ \\
\hline Careiro da Várzea & - & 1 & 3 & 5 & 3 & 3 & - & 1 \\
\hline Iranduba & 9 & 34 & 95 & 44 & 27 & 14 & 11 & 3 \\
\hline Itacoatiara & 6 & 54 & 112 & 61 & 38 & 16 & 11 & 5 \\
\hline Manacapuru & 6 & 71 & 154 & 81 & 42 & 21 & 8 & 4 \\
\hline Manaus & 198 & 2.761 & 7.396 & 3.750 & 1.547 & 684 & 241 & 89 \\
\hline Novo Airão & 1 & 3 & 14 & 18 & 7 & 3 & 3 & 1 \\
\hline Presidente Figueiredo & 2 & 17 & 59 & 48 & 25 & 13 & 9 & 6 \\
\hline Rio Preto da Eva & - & 11 & 31 & 29 & 18 & 13 & 5 & 1 \\
\hline
\end{tabular}

Fonte: SIM/Datasus.

O grupo etário de 30 a 39 anos é uma das faixas etárias que ainda concentra elevada participação nestas cidades. Essa categoria ocupa o segundo lugar nas agressões para a Região Metropolitana de Manaus e segue a tendência de que à medida que a idade se eleva, as ocorrências são reduzidas. No entanto pesa a questão de se perceber que mesmo em idades elevadas, ainda persistam tantas fatalidades, sobretudo na capital, local de maior acúmulo populaional.

\section{Considerações Finais}

O presente trabalho se ocupou em fazer observações relacionadas às mortes por causas externas na Região Metropolitana de Manaus (RMM). Buscou, especificamente observar esta questão com foco nos afogamentos e submersões acidentais e agressões. O período compreendeu uma linha de tempo de 1996 a 2019, com dados extraídos do Sistema de Informação de Mortalidade (SIM/Datasus).

Em relação aos afogamentos e submersões acidentais percebeu-se que em função do fato de que na Região Metropolitana de Manaus todos os oito municípios apresentarem similaridades hídricas, os eventos são presentes. As cidades seguem suas atividades fazendo uso deste recurso, o que se pode considerar que são diversos os fatores que podem atuar conjuntamente para os resultados, tais como: embarcações com lotação acima da sua capacidade; falta de habilidade com o nado por parte dos usuários; não utilização de equipamento de proteção nestas embarcações, bem como a associação de bebida alcoólicas com as ações recreativas nos balneários e locais de lazer.

Manaus, é a cidade que apresenta os maiores eventos e tem em seus portos, intensa movimentação comercial que funciona ainda em moldes não apropiados para a proteção e segurança dos trabalhadores das atividades relacionadas ao 
embarque e desembarque. Esse cenário se replica para os demais municípios. Os resultados apontam que as peculiaridades geográficas do estado do Amazonas colaboram para os índices de afogamentos nestas cidades e que há a necessidade de se trabalhar políticas públicas educativas voltadas para os cuidados com as atividades desenvolvidas sobre as águas e por meio dela.

$\mathrm{Na}$ questão dos óbitos por agressões, tem-se números em tendência de crescimento tanto para a cidade de Manaus quanto para Manacapuru, Itacoatiara e Iranduba. De outro modo, mostra ainda que as agressões são uma das causas de morte que se eleva na linha de tempo estudado, o que retrata que se trata de uma anomalia que atinge significativa parcela da sociedade. Para trabalhos futuros, pode-se desenvolver estudos que primem em mostrar a evolução das políticas públicas para as duas variáveis estudadas, na tentativa de se perceber se há um compasso ou descompasso na tratativa da realidade dos municípios, não apenas da Região Metropolitana, mas para todo o estado, uma vez que a problemática é muito parecida, diferindo apenas de local.

\section{Referências}

Branche, C. M. (1998). What is really happening with drowning rates in the United States? In: Fletemeyer JR, Freas SJ, editors. Drowning - New Perspectives on Intervention and Prevention. CRC Press, 31-42.

Camarano, A. A. et al. (1997). Transformações no padrão etário da mortalidade brasileira em 1979-1994 e seu impacto na força de trabalho. Ipea, 31 p. (Texto para Discussão, n. 512).

Cerdeira, D., \& Moura, R. L. (2014). Demografia e homicídios no Brasil. In: Novo regime demográfico: uma nova relação entre população e desenvolvimento? / Ana Amélia Camarano (Organizadora). Ipea, 2014. 658 p.

CerqueirA, D. \& Moura, R. L. (2013). Custo da juventude perdida no Brasil. Ipea.

Denicola L.K, et al. Submersion injuries in children and adults. Crit Care Clin 1997. 13:477-502.

Ferreira, R. S. A. et al. (2021). Demonstração temporal dos óbitos por causas externas em crianças e adolescentes do Amazonas: considerações por microrregiões. In: Temas atuais de direitos da criança e adolescente. Tirant Lo Blanch Brasil: Rio de Janeiro.

Ferreira, R. S. A. et al. (2021). Temporal demonstration of deaths resulting from physical attacks in the State of Amazonas. Research, Society and Development, 10(2).

Grisso, T. (1996). An interdisciplinary approach to understanding aggressive behavior in children. In C. F. Ferris \& T. Grisso (Orgs.), Understanding aggressive behavior in children (pp. 1-7). The New York Academy of Sciences.

Jorge, MHPM et al (2021). O sistema de informações sobre mortalidade: problemas e propostas para o seu enfrentamento II - Mortes por causas externas. Revista Brasileira de Epidemiologia. 5(2)

Kanso, S. (2014). Compressão da mortalidade no Brasil. In: Novo regime demográfico: uma nova relação entre população e desenvolvimento? / Ana Amélia Camarano (Organizadora). Ipea. 658 p.

Kristensen, C. H et al. (2003). Fatores etiológicos da agressão física: uma revisão teórica. Estudos de Psicologia (Natal). 8(1), $175-184$.

Leite, F. M., et al. (2017) Análise da tendência da mortalidade feminina por agressão no Brasil, estados e regiões. Ciência \& Saúde Coletiva. 22(9).

Mezzaroba, O., \& Monteiro, C. S. (2009). Manual de metodologia da pesquisa no direito. Saraiva. 344 p.

Nóbrega Jr, J. M. et al. (2011). Mortes por agressão em Pernambuco e no Brasil: um óbice para a consolidação da democracia. Rev. Sociol. Polít., 19(40), 4358 .

Oliveira, J. C.; \& Albuquerque, F. R. P. C. (2005). A mortalidade no Brasil no período 1980-2004: desafios e oportunidades para os próximos anos. IBGE.

Pagani, H. M. I. (2014). Comparação de diferentes Métodos de Previsão em Séries Temporais com valores discrepantes. Monografia de Graduação da Universidade Federal de Juiz de Fora. 29 f.

Perrone L. (1977). Metodi Quantitativi della Ricerca Sociale. Feltrinelli, Milão.

Serapione, M. (2000). Métodos qualitativos e quantitativos na pesquisa social em saúde: algumas estratégias para a integração. Ciência \& Saúde Coletiva, 5(1):187-192.

Silva, M. T. \& Galvão, T. F. (2015). Uso de serviços de saúde entre adultos residentes na Região Metropolitana de Manaus: inquérito de base populacional.

Szpilman, D. A. (2000). Afogamentos: Artigo de revisão. Rev Bras Med Esporte. 6(4).

Waiselfisz, J. J. (2012). Mapa da violência 2012 atualização: Homicídios de mulheres no Brasil. CEBELA-FLACSO. 